\title{
A survey of the teaching of conscious sedation in dental schools of the United Kingdom and Ireland
}

\author{
J A Leitch, ${ }^{1}$ N M Girdler ${ }^{2}$
}

\begin{abstract}
Aim To assess and compare, for the first time, the quantity and quality of dental undergraduate teaching in conscious sedation in the dental schools of the UK and Ireland. This was achieved using a prospective, questionnaire-based survey.

Methods Questionnaires were designed to collect information about undergraduate sedation education from teaching staff and final year dental undergraduates at the 16 dental schools in the UK and Ireland. Staff questionnaires were distributed to a nominated sedation teacher at each dental school and sought details of didactic and clinical sedation teaching methods, plus the quantity and perceived quality of sedation teaching. Student questionnaires were distributed to 5 th year dental students and enquired about the quantity and quality of clinical sedation teaching received. The survey was undertaken during May-June 1998.
\end{abstract}

Results Thirteen dental schools returned staff questionnaires $(81 \%)$. Seven also provided a student response $(44 \%)$. The proportion of final year students within the 7 schools who returned completed questionnaires was $38 \%$. Sedation teaching was undertaken primarily by oral surgery and paediatric dental departments. Three schools also utilised anaesthetic departments and 2 schools had dedicated dental sedation departments. All but 2 schools provided didactic teaching on sedation (mean: 4.2 lectures, 1.8 seminars). Of the 7 schools which returned staff and student questionnaires, all provided some clinical training using inhalational and intravenous demonstration cases (mean 5.1 and 4.4 cases, per student, respectively). All but one school provided hands-on inhalational sedation experience (mean 2.6 cases per student) but only two schools provided any hands-on intravenous sedation experience. The quantity of hands-on experience was greater at the two dental schools with dedicated dental sedation departments. Across the schools students rated the overall quality of sedation teaching at average or above, but most staff graded the overall quality of teaching at below average.

Conclusion Dental undergraduate sedation teaching shows considerable variation across the dental schools surveyed. At most schools students gained little or no handson experience in sedation, especially in intravenous techniques. The undergraduate foundation for sedation education must improve if conscious sedation is to become the principal alternative to general anaesthesia in dental practice.

$\mathrm{H}$ istorically the practice of dentistry has had a powerful association with pain and anxiety. Negative perceptions about the speciality still persist despite modern advances in methods of analgesia and anxiolysis. In the last UK adult dental health

\footnotetext{
${ }^{1}$ Staff Grade Oral Surgeon, Glasgow Dental Hospital \& School, Sauchiehall Street, Glasgow

${ }^{2}$ Consultant Senior Lecturer, University of Newcastle Dental School \& Hospital, Framlimgton Place,

Newcastle Upon Tyne.

* Correspondence to Dr NM Girdler.

REFEREED PAPER

received 12.04.99; accepted 15.07.99

(C) British Dental Journal 2000; 188: 211-216
}

survey over $45 \%$ of the adult population claimed that fear was a major barrier to dental care. ${ }^{1}$ As a result many anxious or phobic dental patients require the support of pharmacological methods of sedation to enable them to undergo routine dental treatment. ${ }^{2}$

The use of conscious sedation is becoming increasingly important as a safe and effective method of anxiolysis for use by dental practitioners. ${ }^{3}$ Education of dentists in the use of conscious sedation is undertaken at both undergraduate and postgraduate levels. Although postgraduate training is mandatory before a dentist can practice

\section{In brief}

- The quantity and quality of undergraduate sedation teaching varies considerably across the UK and Irish dental schools.

- Students at most dental schools are failing to receive adequate hands-on sedation experience, especially in intravenous techniques.

- Undergraduate sedation training must improve if conscious sedation is to become the principle alternative to $G A$ in dental practice.

sedation, the undergraduate curriculum is expected to provide a thorough introduction to the subject. ${ }^{4}$

The UK General Dental Council recommends that undergraduate dental students should:

- Have a sound knowledge of the basic sciences relevant to sedation

- Be capable of selecting suitable cases for pharmacological sedation

- Have practical experience in the administration of inhalational and intravenous sedation and

- Have practical experience of operating on sedated patients. ${ }^{4}$

Other educational bodies have also made recommendations on undergraduate sedation education. The Joint Dental Faculties of the Royal College of Surgeons of England ${ }^{5}$ and the UK Department of Health ${ }^{6}$ both highlighted a perceived deficiency in undergraduate sedation training and made appropriate proposals. These official statements, guidelines and recommendations form the benchmark against which the quality of sedation care and teaching must be judged.

To date there has been no published data, which describes the quantity and quality of undergraduate sedation education undertaken at individual dental schools in the UK 
and Ireland. Limited information is available from the report of the General Dental Council visitation to the UK dental schools, ${ }^{7}$ a survey undertaken on behalf of the Poswillo working party ${ }^{6}$ and anecdotal communications from individual teachers, all of which suggest that there is considerable variability in undergraduate sedation teaching across the UK and Ireland. A national survey commissioned by the UK Department of Health which addressed how undergraduate education prepared new graduates for their first year of general practice revealed that new graduates felt inadequately prepared in the field of sedation (in addition to other subjects). ${ }^{8}$ This survey gave a good indication of general inadequacies in the educational process but due to its broad scope could offer no specific information about problems or solutions.

The aim of this study was to assess and compare the quantity and quality of education in conscious sedation provided at each of the dental schools in the UK and Ireland. The objective was to obtain accurate data, based on information gained from both teachers and students, upon which recommendations could be made about future dental undergraduate sedation education.

\section{Materials and Methods}

The study was designed as a prospective, questionnaire-based survey. The survey was undertaken during May-June 1998.

\section{Questionnaire design}

Two questionnaires were designed. The first sought to obtain information from members of staff responsible for teaching sedation. The second was targeted at 5 th year students who were just about to sit their final examinations. The questionnaires were designed to ensure brevity and ease of completion.

\section{i. Staff Questionnaire}

This questionnaire targeted the quantity of both didactic and clinical teaching and sought an overall assessment of teaching quality. The questions are summarised as follows:

- Which dental school do you represent?
- Which departments in your institution undertake sedation teaching?

- What form does the sedation teaching take?

- Specify numbers of lectures and seminars on sedation.

- Specify how many demonstration and hands-on, inhalational and intravenous sedation cases each student is expected to observe and undertake.

- How would you rate the adequacy of sedation teaching in your dental school? ( $5=$ very satisfactory, $4=$ satisfactory, $3=$ average, 2 = unsatisfactory, $1=$ very unsatisfactory)

- Do you have any other comments on undergraduate sedation teaching?

\section{ii. Final Year Student Questionnaire}

This questionnaire primarily addressed the quantity and quality of clinical teaching. Similar questions to those on the staff questionnaire were used to allow comparison with staff responses. The questions are summarised as follows:

- Which dental school do you attend?

- How many demonstrations and handson, inhalational and intravenous sedation cases have you observed, and performed, during your undergraduate course?

- How would you rate the adequacy of sedation teaching which you have received? $(5=$ very satisfactory, $4=$ satisfactory, 3 = average, 2 = unsatisfactory, 1 $=$ very unsatisfactory).

- Do you have any other comments about the sedation teaching?

\section{Questionnaire Distribution}

Staff and student questionnaires were supplied to a single staff representative of each of the 14 UK dental schools and the 2 Irish dental schools. The member of staff selected from each dental school was that school's nominated representative on the Dental Sedation Teachers Group. An envelope containing an explanatory letter, a staff questionnaire, student questionnaires and a return postage-paid envelope was supplied to each representative. Four weeks later a follow-up reminder was sent to those dental schools which had not yet returned the completed questionnaires.

Data analysis

Data from the returned questionnaire were entered onto an Excel spreadsheet. Quantitative analyses were confined to simple summation of variables and estimation of means for each variable. As there were a number of student responses from each school a mean response (expressed to the nearest whole number) was calculated for each question. This was considered sufficient to allow an overall comparison of data between different dental schools and a comparison between staff and student responses within a single dental school. Detailed statistical analysis would have been unjustified in view of the subjective nature of much of the information.

\section{Results}

Of the 16 dental schools surveyed, completed staff questionnaires were received from 13, giving a response rate of $81 \%$ (Table 1). Completed student questionnaires were received from seven schools (44\%). The number of individual students from each school who responded ranged from $23-80 \%$ of the number of final years in the respective school. One hundred and seventy-three student responses were received, out of a total of 455 final year students at the 7 schools, giving a overall student response rate of $38 \%$. Three schools failed to provide any response (staff or student), despite active follow-up.

The departments which contribute to sedation teaching at each dental school, are shown in Table 2. Only two schools ( $\mathrm{J}$ and $\mathrm{R}$ ) have dedicated departments of dental sedation. Most other schools utilised a combination of oral surgery and paediatric dental departments. Four also used restorative departments to share this role. At two schools (A and $\mathrm{K}$ ) sedation is taught exclusively by the oral surgery departments. Three schools (E, H and L) used their anaesthetic departments, in addition to dental departments, for the teaching of sedation.

The quantity of didactic sedation teaching, using lectures and seminars, in each dental school is shown in Figure 1. This data is based on responses from staff 
questionnaires only. There is considerable variation in the total number of lectures undertaken at each school, ranging from 10 in school $\mathrm{P}$ to nil in schools $\mathrm{F}$ and $\mathrm{S}$. There is a similar variation in quantity of seminars, ranging from 6 in school $\mathrm{H}$ to none in Schools E, F, L and S. The mean quantity of lectures and seminars undertaken across the 13 dental schools who responded, is 4.2 and 1.8 respectively. Two schools (F and S) apparently undertake no sedation teaching using didactic methods.

The quantity of clinical training in sedation, using demonstration and hands-on cases, is shown in Figures 2 and 3. The results in this section are restricted to the 7 schools which returned both student and staff responses. It was considered essential, when assessing quantity of clinical training, to have actual student responses, in addition to staff perceptions of clinical exposure. Although the relatively low student response rate $(38 \%)$ negates detailed interpretation of the results due to potential bias, the data are useful for comparative purposes and for identifying general trends.

Figure 2 shows the number of demonstration cases seen by each student. The data have been sub-divided into inhalational and intravenous cases, with staff and students responses being shown separately. The considerable variation between dental schools and also, for some schools, between the staff and student responses is evident.

Students at schools $\mathrm{H}$ and $\mathrm{R}$ experienced

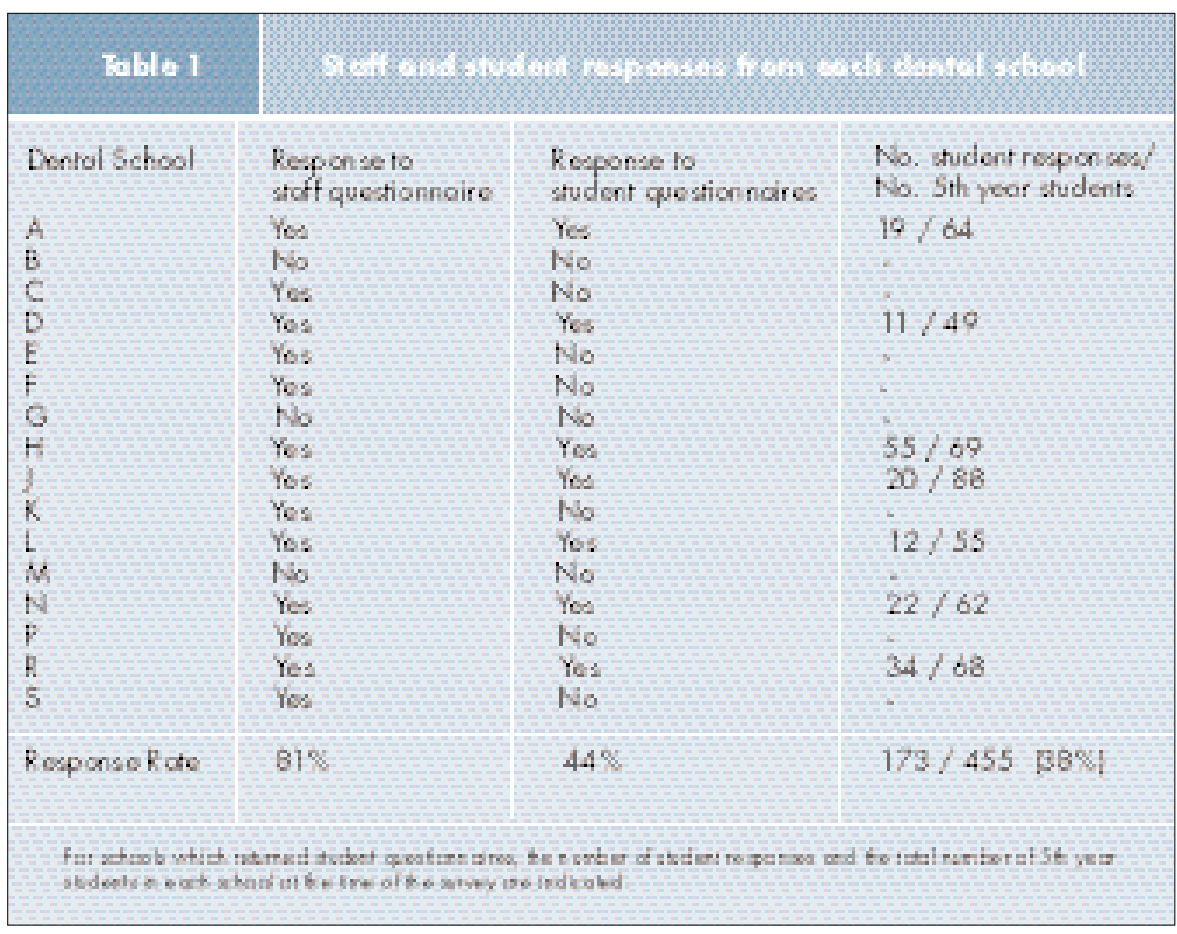

the greatest number of inhalational demonstration cases (10 and 8 cases respectively). Students at the other schools observed an average of 5-6 cases, except at schools A and L, where students only saw 1-2 cases. Students at school R saw the greatest number of intravenous demonstration cases (8). Students at the other schools observed 4-6 cases, except for two schools (A and L) where students only saw 1-2 intravenous cases. The mean number of inhalational and intravenous demonstration cases reported by students across the seven schools was 5.1 and 4.4 respectively.

Data from the staff questionnaires indicated that the mean number of inhalational and intravenous demonstration cases that staff thought students had been exposed to were 4.7 and 5.7 respectively. Staff slightly underestimated the number of inhalational cases and slightly overestimated the quantity

\begin{tabular}{|c|c|c|c|c|c|}
\hline \multirow{2}{*}{$\begin{array}{l}\text { Tobla } 2 \\
\text { Dentol } \\
\text { Schod }\end{array}$} & \multicolumn{5}{|c|}{ 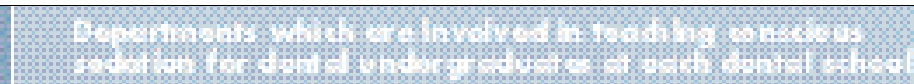 } \\
\hline & $\begin{array}{l}\text { Onol } \\
\text { surgory }\end{array}$ & $\begin{array}{l}\text { Poodictric } \\
\text { dentialy }\end{array}$ & $\begin{array}{l}\text { Retcrotive } \\
\text { dentitry }\end{array}$ & Anoosticeio & Sodution \\
\hline $\begin{array}{l}A \\
C \\
D \\
E \\
H \\
H \\
j \\
K \\
E \\
N \\
P \\
k \\
S\end{array}$ & $\begin{array}{l}x \\
x \\
x \\
x \\
x \\
x \\
x \\
x \\
x\end{array}$ & $\begin{array}{c}x \\
x \\
x \\
x \\
x \\
x \\
x \\
x \\
x \\
x\end{array}$ & $\begin{array}{l}x \\
x \\
x\end{array}$ & $\begin{array}{l}x \\
x\end{array}$ & $x$ \\
\hline
\end{tabular}

of intravenous cases observed by students.

Figure 3 shows the quantity of hands-on cases undertaken by each student. The data have again been subdivided into inhalational and intravenous cases, with separate staff and student responses. The most noticeable feature is the substantial variation between schools.

At schools J and R, students undertook an average of 5 inhalational and 4 intravenous cases. The other schools provided some hands-on inhalational sedation experience (ranging from 1-4 cases), with the exception of school N, which did not provide any. All schools, apart from two ( $\mathrm{J}$ and R), failed to provide any hands-on experience in intravenous sedation. The mean numbers of hands-on inhalational and intravenous cases reported by students across all seven schools was 2.6 and 1.1 respectively.

Staff estimations of the quantity of hands-on experience gained by students showed more digression than for the demonstration cases. The mean number of hands-on cases reported by staff across the seven dental schools were 2.1 inhalational cases and 2.4 intravenous cases. Staff slightly underestimate the quantity of inhalational cases and substantially overestimate the number of intravenous cases undertaken by students.

The evaluation of quality of sedation teaching at the 7 schools from which student and staff responses were received is shown in Figure 4. Students at school $\mathrm{R}$ rated the teaching as very satisfactory. At four other schools (A, D, J and N) the teaching was rated as satisfactory. At school $\mathrm{H}$ students rated the teaching as average and at school L 


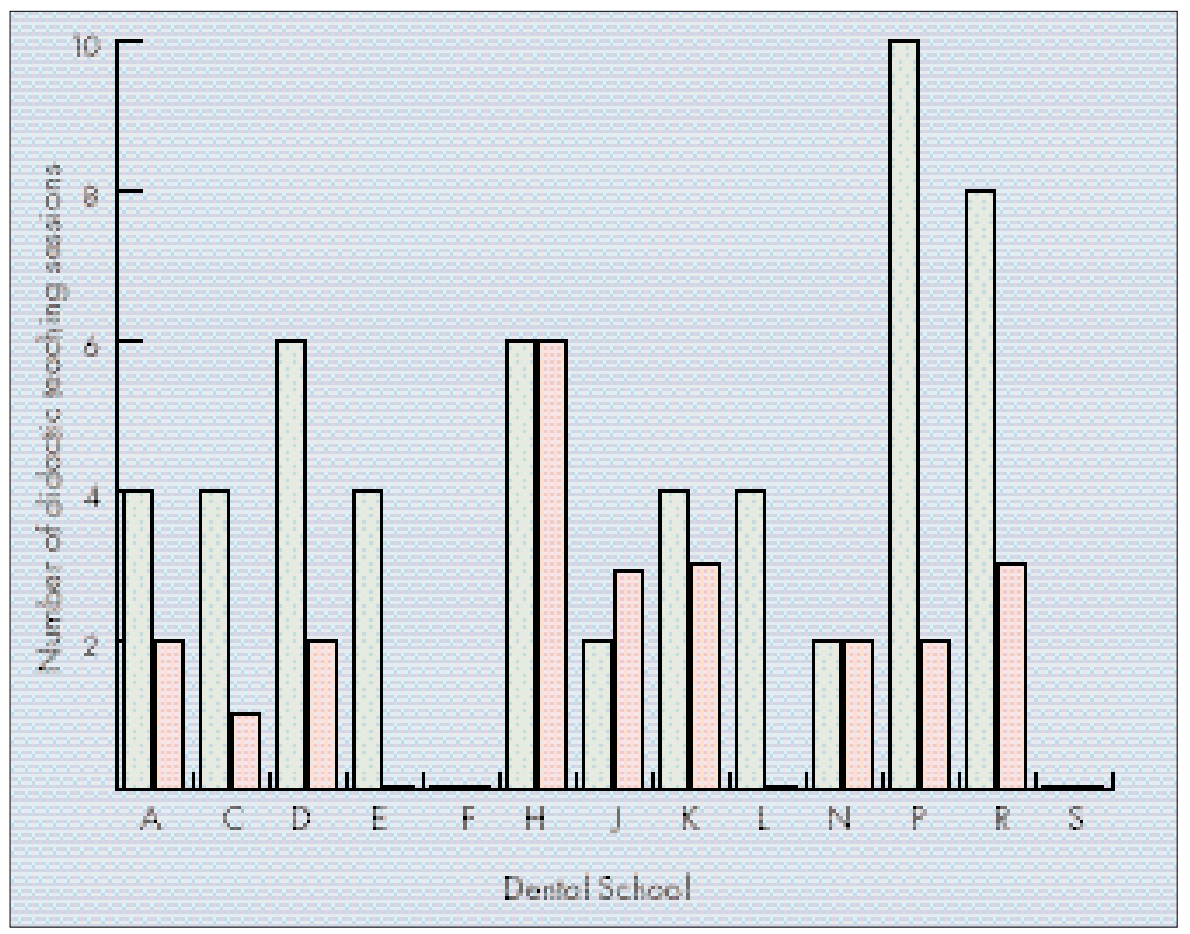

as unsatisfactory. Staff at three schools (A, L and $\mathrm{R}$ ) allocated the same quality rating as their students, but at three other schools (D, $\mathrm{H}$ and $\mathrm{N}$ ) staff measured the quality of teaching as less satisfactory than the students' rating. At school J the staff score was higher than that of the students.

A number of comments were made by individual staff in the open part of the questionnaire. A summary of the comments is listed below:

- 'Sedation is seen as separate subject, not as an adjunct to treatment.'

- 'We need greater facilities to be able to implement hands-on training for the students.

- 'Not enough teachers, insufficient time in the curriculum, inadequate facilities'

- 'Insufficient staff to supervise sedation'

- 'Not enough hands-on practice to enable students to be proficient.'

- 'The teaching is left to one department; there is a flat refusal to introduce sedation into other departments.'

- 'Regarded heavily as a postgraduate subject.'

- 'Very under-funded.'

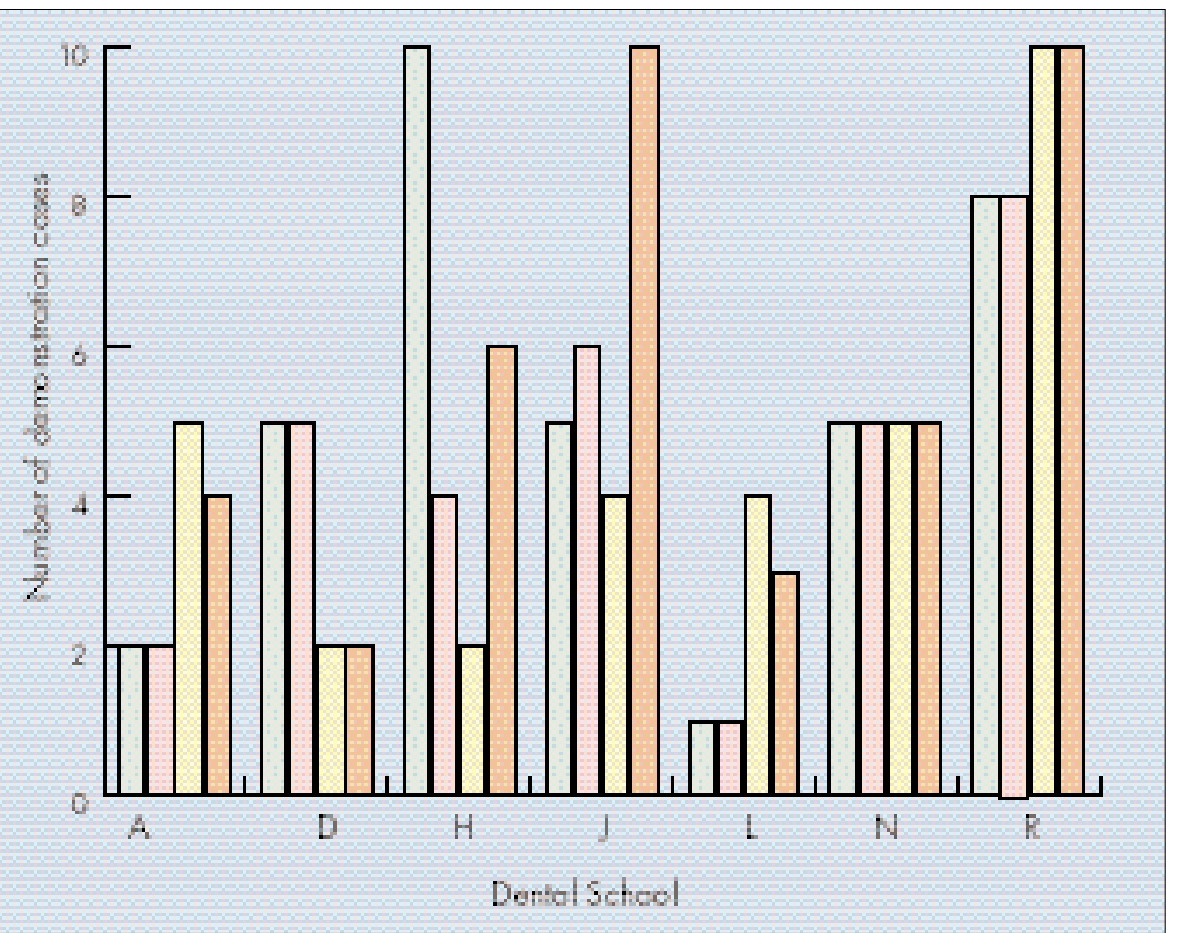

Fig. 1 Quantity of didactic sedation teaching (lectures and seminars) reported by staff from each dental school. Green, lectures; red, seminars.

There were no additional comments in the open section of any of the student questionnaires.

\section{Discussion}

The response rate of $81 \%$ obtained for the staff survey was gratifying. Staff questionnaires were completed by nominated representatives of each dental school on the Dental Sedation Teachers Group. In this respect the response was considered to be a valid indication of sedation teaching at each school. Unfortunately less than half (44\%) of the dental schools surveyed managed to return completed student questionnaires and the proportion of students responding within these schools was only $38 \%$. The low student response was primarily due to difficulty in recruitment caused by timing of the survey around the period of final examinations. For the schools which did provide both staff and student responses it was possible to compare actual student experience with staff expectations for the clinical parts of the course. Although the low student response limited detailed interpretation, it was possible to identify general trends and make overall comparisons.

The majority of sedation teaching, in the 13 dental schools which responded, is undertaken by oral surgery and paediatric dental departments. It is likely that paediatric sedation education would target mainly inhalational sedation, as this is the method of choice in the UK and Ireland for sedating paediatric dental patients. ${ }^{9}$ Intravenous techniques are primarily used in adults ${ }^{10}$ and thus it is probable that those departments of oral surgery and restorative dentistry involved in sedation education would take the lead in teaching intravenous sedation. It is interesting to note that only 3 dental schools use departments of anaesthesia to provide input into sedation education, although collaboration between dental teachers and anaesthetic departments is recommended by the UK General

\section{Fig. 2 Quantity of clinical sedation} teaching (demonstration cases) reported by students and staff at each dental school. Green, student intrahalational; red, student intravenous; yellow, staff inhalational; orange, staff intravenous. 


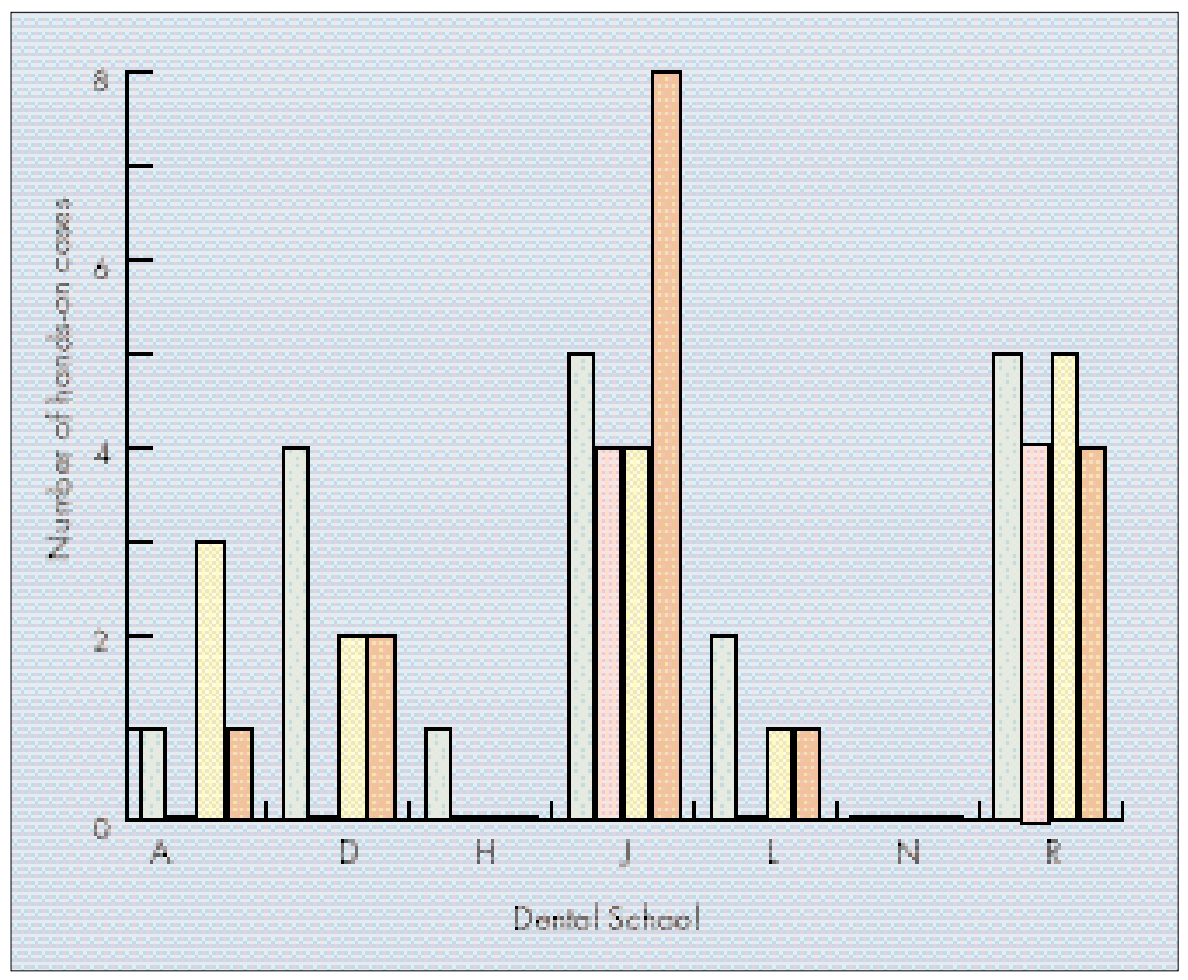

Dental Council. ${ }^{4}$ Only 2 dental schools have departments of sedation, which are dedicated to teaching sedation for dental purposes. Accordingly the recommendation that all UK dental schools should create specific academic posts in dental sedation appears to be long way from being fulfilled. ${ }^{11}$

The quantity of didactic and clinical teaching in sedation varies considerably from school to school. Eleven out of the 13 dental schools which responded provide some form of theoretical introduction to conscious sedation, using lectures and/or seminars. There was a significant variation between schools in the numbers of lectures and seminars provided, ranging from 2-10 and 1-6 respectively. Two dental schools apparently provide no theoretical sedation teaching. In an already crowded curriculum it is difficult to negotiate extra teaching time for didactic teaching but it is clear that some schools are achieving this with greater success than others. However, a sound theoretical background to the principles of sedation is essential before students can be expected to move onto learning practical sedation techniques. ${ }^{4}$

Practical experience in both inhalational and intravenous sedation is a key component of sedation education., ${ }^{4,6}$ It was

Fig. 4 Student and staff assessment of the adequacy of sedation teaching at each dental school ( 1 = very unsatisfactory, 2 = unsatisfactory, 3 = average, 4 =

satisfactory, 5 = very satisfactory). Green, student; red, staff.
Fig. 3 Quantity of clinical sedation teaching (hands-on cases) reported by students and staff at each dental school. Green, student intrahalational; red, student intravenous; yellow, staff inhalational; orange, staff intravenous.

questionnaires were analysed in this part of the study.

Each of the 7 schools provides some training in inhalational and intravenous sedation using demonstration cases, although there is wide variation in the number of cases between different schools. The opportunity for students to gain hands-on experience in sedating patients is more limited. All dental schools, with the exception of one, provide hands-on training in inhalational sedation, but only two schools provide students with hands-on experience in intravenous sedation. It is interesting that the two schools with dedicated sedation departments (schools J and $\mathrm{R}$ ), are the only institutions where students report actual hands-on clinical experience with intravenous techniques. Even in these two schools each student only undertakes an average of four intravenous cases.

Comparison of student with staff responses, for the 7 schools, indicates that staff slightly underestimate the number of inhalational demonstration cases and slightly overestimate the intravenous demonstration cases seen by their students. A similar staff underestimation was seen for

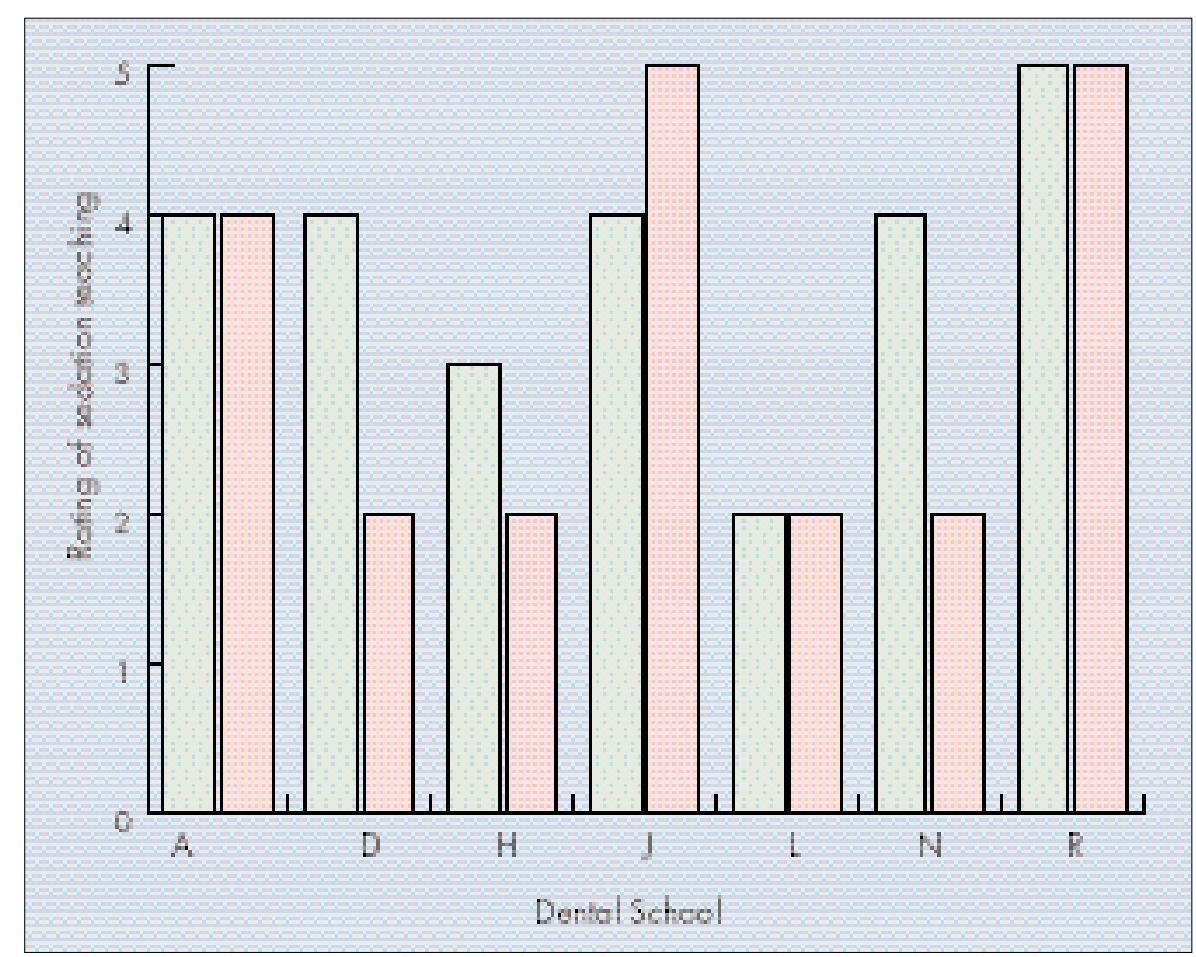


hands-on inhalational cases. However, there was a substantial over-estimation of the amount of hands-on intravenous experience; students actually treated less than half the number of cases estimated by staff.

The dental undergraduate curriculum issued by the UK General Dental Council emphasises that students should have practical experience in the administration of both inhalational and intravenous sedation. ${ }^{4}$ Of the 7 schools which submitted staff and student responses, most are providing some inhalational sedation experience but few give students any experience in intravenous techniques. If those dental schools with and without sedation departments are compared it is clear that those with departments dedicated to sedation teaching have the highest numbers of both observed and performed cases. There suggests a quantifiable advantage to those schools with departments and staff dedicated solely to sedation education.

It is important not only to evaluate the quantity of sedation education but also to assess the quality. Overall the students who responded were generous in their grading of quality of teaching in sedation. At 6 out of the 7 schools which provided student responses, the students rated sedation teaching as average or above, and one school received maximum marks. Staff were more pessimistic, with only three rating sedation teaching at their respective school as average or above. Lack of staff and poor facilities for sedation teaching, plus the low profile of sedation in the undergraduate curriculum, were cited by individual staff as reasons for their pessimism. There appeared to be little correlation between students' perceptions of teaching quality and actual experience. Most students thought that they were receiving an adequate sedation education despite the fact that national recommendations for sedation training at most schools were far from being achieved. ${ }^{4,6}$

Interpretation of the results of this survey must be viewed in the light of the low number of schools offering any student response and the low proportion of students within those schools who returned completed questionnaires. However, for those 7 schools which were analysed it is clear that the number of sedation cases being undertaken by students falls far short of the 10 inhalational and 5 intravenous cases recommended by Poswillo. ${ }^{6}$ The General Anaesthesia and Sedation Review Group of the UK General Dental Council indicated that undergraduate training in administering intravenous and inhalational sedation and in treating patients under sedation is inadequate. ${ }^{11}$ It is now possible, in the light of this survey, to provide substantive evidence that undergraduate training is indeed inadequate. In all but 2 of the 7 UK dental schools analysed there appears to have been minimal response to the recommendations arising of the General Dental Council's Dental School Visitation Report. ${ }^{7}$

Sedation teaching at undergraduate level seems to have been afforded a low priority by many dental schools. Ironically, this is at a time when the clinical demand for sedation is predicted to increase. ${ }^{12}$ The impact of the new UK General Dental Council guidelines on general anaesthesia is likely to further enhance the need for sedation services in dental practice. ${ }^{13}$ It is essential that practitioners wishing to undertake sedation are appropriately trained, and the basis for postgraduate sedation education must start in the undergraduate course. ${ }^{5}$ The results of this study confirm the perception among dental educators of the variable quality of sedation teaching, especially the lack of practical experience. The responsibility for action lies with individual dental schools and dental regulatory bodies. Both must take action to develop sedation education in the undergraduate dental curriculum.

The authors are grateful to the Chairman (DrND Robb) and Committee of the Dental Sedation Teachers Group for completing staff questionnaires and for administering the student questionnaires., and to the Northern Region Postgraduate Institute for Medicine and Dentistry. This study was undertaken as part of the Diploma of Consious Sedation of the University of Newcastle.

1 Todd J E, Lader D. Adult dental heath. London: HMSO, 1991.

2 Ryder W, Wright PA. Conscious sedation: A review. Br Dent J 1988; 165: 207-216.

3 Girdler N M, Hill C M. Sedation in Dentistry. Oxford: Butterworth Heinemann, 1998.

4 General Dental Council. The first five years: the undergraduate dental curriculum. London: General Dental Council, 1997.

5 Royal College of Surgeons of England. Report of the Joint Dental Faculties Working Party on Sedation. London: Royal College of Surgeons of England, 1993.

6 Poswillo D E. General anaesthesia, sedation and resuscitation in dentistry: Report of an Expert Working Party for the Standing Dental Advisory Committee. London, Department of Health, 1990.

7 General Dental Council. Report of the visitation to dental schools 1993-1995. London, General Dental Council, 1995.

8 Levine R S. Experience, skill and knowledge gained by newly qualified dentists during their first year of general practice. Br Dent $J 1992$; 172: 97-102.

9 Crawford A N. The use of nitrous oxide-oxygen inhalational sedation with local analgesia as an alternative to general anaesthesia for dental extractions in children. Br Dent $J 1990 ; 168$ 395-398.

10 Skelly A M. Sedation in dental practice. Dental Update 1992; 19: 61-67.

11 General Dental Council. Report of the General Anaesthesia and Sedation Review Group. London, General Dental Council, 1996.

12 Seward M. GA — end of an era. Br Dent J 1998; 185: 497.

13 General Dental Council. Maintaining standards: Guidance to dentists on professional and personal conduct. London: General Dental Council, 1998. 